\title{
An Exploration Of Improved Design Of Biomass Pyrolysis Liquefaction Device
}

\author{
Yue Xia \\ College of Mechanical, Inner Mongolia University of Technology, Hohhot, China \\ 18947163882,e-mail: yuexia995@126.com
}

KeyWords: Biomass; Pyrolysis Liquefaction Device; Improved Design

\begin{abstract}
With people's long-term exploitation, reserves of fossil fuels are continuously reducing, then in order to meet demand of social development for energies, developing renewable clean energies has attached with more and more importance. Biomass energy is renewable and environmentally friendly, so it has become a research emphasis. Application of biomass energy needs specialized biomass pyrolysis liquefaction device to process. This paper analyzed fluidized bed biomass pyrolysis liquefaction device, based on which it proposes optimization method of this device for reference.
\end{abstract}

\section{Introduction}

Biomass pyrolysis liquefaction refers to the process of rapidly heating biomass under oxygen deficit or oxygen-free conditions to generate complicated chemical reactions like micro-molecular polymerization, heterization and molecular bond rupture inside biomass and then converting biomass into liquid bio-oil. The whole process involves many subsystems and equipments such as condensing system, cyclone separation system, fluidized bed reactor, feeding system, etc ${ }^{[1]}$. Improved design of related subsystems and equipments is of great significance to improving conversion efficiency and quality.

\section{Analysis of Biomass Pyrolysis Liquefaction Device}

\subsection{Feeding System}

During biomass pyrolysis liquefaction process, feeding evenness of feeding system exerts great influence on pyrolysis liquefaction effect. Spiral feeding technology in feeding system has been extensively applied by virtue of its advantages like easy industrialization, strong conveying capacity and simple structure. What this paper analyzes is two-stage spiral feeding system which mainly consists of first-stage screw, second-stage screw, electrode variable-frequency and variable-speed motor, feeding cylinder and so on, whereby the feeding cylinder is connected with first-stage feeding screw through conical foundation and cast steel shell. First-stage and second-stage screws consist of variable-frequency and variable-speed motor controller and motor drive Biomass materials are stored in feeding cylinder, through which they enter first-stage screw, and then they enter second-stage screw and rapidly enter fluidized bed. Effect of first-stage screw lies in quantifying charged materials and that of second-stage screw is rapidly feeding.

\subsection{Fluidized Bed Reactor}

Reactor is a key equipment of pyrolysis, whereby gaseous phase standing time, reaction temperature and heating rate are important indexes. Fluidized bed reactor is a kind of device which uses liquid or gas to pass through solid particle layer from top to bottom so as to make particles under state of suspension to experience liquid-solid phase or gas-solid phase reaction ${ }^{[2]}$.

\subsection{Cyclone Separation System}

Cyclone separator is equipment which uses rotational motion of gas-solid phase fluid to realize separation of solid particles from airflow under centrifugal effect. Function of separator in cyclone separation system in this paper lies in separating solid carbon particles generated by biomass pyrolysis. Practice indicates that there are many factors influencing gas-solid separation efficiency such as size and structure of separator, diameter of solid particles and so on. Cyclone separation system in this paper uses single-stage cyclone separator with reasonable size and structure and its separation efficiency reaching as high as $95 \%$.

\subsection{Condensing System}

Condenser includes direct-type condenser and indirect-type condenser whereby the latter can be classified into plate-type condenser, coiled tube type condenser and 
tube array type condenser, especially tube array condenser is of convenient installation, and it bears little influence of spatial height and has high utilization efficiency in practical production. Pyrolysis gas products and non-condensing gas during condensing process form smog-shape aerosol form, which greatly increases liquid collection difficulty. In large-scale reaction system, using the method of contacting cold liquid can improve condensation and collection effect. The condenser analyzed in this paper is mainly four-stage tube array type condenser which can obtain good condensing effect.

\section{Optimization of Biomass Pyrolysis Liquefaction Device}

There are some problems in biomass pyrolysis liquefaction device in this paper through experimental verification, which are mainly manifested in: wall-hanging and material-suspending phenomena easily happen to biomass in feed bin, which makes feeding evenness poor; gas-carrying high-purity nitrogen and biogas are directly emitted without processing, which not only increases the cost but also results in great pollution to the environment; temperature in biomass softening process is low while exit end of second-stage screw is of high temperature, discharge port will be blocked because of coking. Hence, improved design should be made for this biomass pyrolysis liquefaction device to avoid occurrence of above bad conditions.

\subsection{Improvement of Feeding System}

In order to avoid undesirable phenomena of material scraping and suspending of biomass in feed bin, the following improvements are made: install spring rod component in feeding battle, use rotation of first-stage screw to provide power, biomass materials are stirred and disturbed through reciprocating vibrations to avoid suspending and bridging phenomena of them in feeding cylinder and ensure continuity of biomass materials entering first-stage screw tank.

Spring rod component includes two starlike brackets and a spring rod. Each starlike bracket consists of fastening bolt, a sleeve, six starlike bracket rods and six contacts. Upper end of spring rod is connected to first-stage screw, and its lower end is fixed cover of feeding cylinder. During feeding process, spring rod is pushed ahead under the influence of first-stage feeding screw, after reaching a certain degree, lower end of spring rod is separated from screw thread, and then spring rod returns to original position. In the meantime, during the designing process, in order to further improve disturbance effect two starlike brackets are designed on spring rod to effective prevent materials in feeding cylinder from generating bridging phenomenon, especially wall of feeding cylinder is collided by contacts of starlike bracket for many times so as to avoid wall hanging phenomenon ${ }^{[3]}$.

\subsection{Improvement of Biomass Pyrolysis Liquefaction} Technology

In order to reduce usage amount of high-purity nitrogen and energy consumption of carrier gas heating and cooling and to realize uttermost recycle of system heat quantity, biomass pyrolysis liquefaction technology is optimized.

On the one hand, pyrolysis gas cyclic design. The temperature of mixed gas of carrier gas flowing out of fluidized bed and pyrolysis gas in biomass pyrolysis liquefaction system is about $500^{\circ} \mathrm{C}$, when a part of mixed gas is processed, it will circulate to backflow bed and be used as carrier gas, which can reduce energy consumption while reducing consumption of high-purity nitrogen. Biomass pyrolysis process is as shown in Figure 1, through one pyrolysis, generated substances are non-condensable gas, primary bio-oil and charcoal, then second pyrolytic reaction occurs and makes some bio-oil be pyrolysed into secondary non-condensable gas and secondary bio-oil. Finally biomass pyrolysis will generate charcoal, non-condensable gas and bio-oil ${ }^{[4]}$. Through verification, the longer gaseous products stayed in reactor, the higher the temperature in reactor will be, and the more violently secondary pyrolysis will proceed. Before pyrolysis gas circulation is taken as carrier gas, standing time of it under high-temperature condition is prolonged to facilitate pyrolysis gas to generate secondary pyrolysis more frequently so as to transform macro-molecular tar into micro-molecular gas and prevent tar from circulating into fluidized bed and bonding biomass particles, and increased secondary pyrolysis products can exert inhibitory effect on secondary pyrolysis of pyrolysis gas and increase yield of bio-oil. 
Tar yield of liquid products should be reduced as much as possible during biomass liquefaction process, tar-elimination processing should be implemented in order to take full advantages of pyrolysis gas, especially for the part of pyrolysis gas which is taken as carrier gas, tar eliminating method in biomass gasification technology can be taken for reference. Temperature of pyrolysis gas leaving from cyclone separator is about $500^{\circ} \mathrm{C}$, especially pyrolysis gas which is cyclically utilized as carrier gas should maintain high temperature, dry method is adopted to eliminate tar, and metal, ceramic and texture filters are used to eliminate condensable tar which is nearly dry from pyrolysis gas.

On the other hand, burning biogas to heat raw materials. Energy consumed by heating biomass raw materials occupies $40 \%$ of total energy consumption, for example, burning biogas can satisfy this part of energy consumption requirement. Hence, burning design is implemented on biogas to heat biomass raw materials, which can not only reduce unnecessary energy consumption but also avoid directly disfeeding into atmosphere and polluting it.

In addition, in consideration of connection between fluidized bed and second-stage feeding spiral exit, the temperature is high, which will result in coking of biomass raw materials by entering fluidized bed, so a cooling water storage is designed at second-stage feeding spiral exit ${ }^{[5]}$.

\section{Analysis of Pyrolysis Liquefaction Device Improvement Results}

On the one hand, analysis of feeding system improvement is made. Firstly, in aspect of feeding speed, before feeding system is improved, under the same rotational speed, there is great difference in feeding speed, when first-stage and secondary-stage rotational speeds are respectively $13.25 \mathrm{r} / \mathrm{min}$ and $300 \mathrm{r} / \mathrm{min}$, their feeding speeds through measurement are respectively 8.40, 7.35, 6.24 and $5.63 \mathrm{~kg} / \mathrm{h}$. This indicates that feeding evenness after improvement of feeding system is obviously elevated. Secondly, in aspect of feeding evenness, when feeding speeds of first-stage feeding before improvement are respectively $13.25,20.75,29.75$ and $38.75 \mathrm{r} / \mathrm{min}$ and those of secondary-stage are respectively 300, 400, 500 and $600 \mathrm{r} / \mathrm{min}$, feeding rotational speed of first stage is not change, feeding speed experiences great fluctuation, when feeding rotational speed of first stage reaches $38.75 \mathrm{r} / \mathrm{min}$, minimum and maximum feeding speeds are respectively $19.54 \mathrm{~kg} / \mathrm{h}$ and $26.40 \mathrm{~kg} / \mathrm{h}$, and average feeding amount is $14.60 \mathrm{~kg} / \mathrm{h}$. The reasons for great fluctuation of feeding speed before improvement are suspending and wall-hanging, while small fluctuation of feeding speed after improvement is mainly caused by errors, and errors meet related standard requirements. Finally, in aspect of feeding and conveying capacity, when feeding rotational speeds of first stage are $38.75,29.75,20.75$ and $13.25 \mathrm{r} / \mathrm{min}$, average feeding speed after improvement is greatly improved when compared with that before improvement. In the meantime, when rotational speed, physical property of materials and equipment size are not changed, feeding speed is mainly influenced by filling coefficient, namely when filling coefficient is large, feeding speed is greater, on the contrary, it will be smaller. Thus it is not difficult to find that device improvement elevates filling degree of materials in spiral. Especially designed spring rod damages the balance between wall hanging and bridging of materials in feeding cylinder, which is equivalent to lengthening effective length of compression segment of spiral conveyor, improving material compaction degree of spiral conveyor and increasing filling coefficients. Under the same rotational speed, feeding speed after improvement can be twice as that before improvement.

On the other hand, technology improvement results are analyzed. It's found by analyzing improved technology that usable heat quantity in the system can be recycled well, which reduces energy consumption of carrier gas heating and cooling, especially consumption of high-purity nitrogen is obviously reduced and production cost is decreased. In the meantime, preventing exhaust gas emitting into air is of great significance to protecting the environment. Moreover, a cooling water storage is designed at secondary-stage feeding spiral exit to reduce temperature of feeding screw and avoid coking phenomenon of biomass materials.

Fund project: Design of biomass pyrolysis device with blast furnace slag as heat carrier. No.X201603

\section{References}

[1]Zhao Jun. Design Theory and Simulation Research of 
Suspension and Fluidization-Type Biomass Pyrolysis Liquefaction Device [D]. Northeast Forestry University, 2008.

[2]Li Hui, Ma Xinhui. Improved Design of Biomass Pyrolysis Liquefaction Device [J]. New Technique and New Technology, 2015,01:129-130.

[3]Li Yongjun. A Study of Experimental Facility of Downcomer-Type Biomass Pyrolysis Liquefaction [D].
China Agricultural University, 2004.

[4]Ma Xinhui. Simulation Study of Biomass Pyrolysis Liquefaction Device and Fluidized Bed Cold State[ D]. Zhengzhou University, 2006.

[5]Liu Shifeng, Wang Shuyang. Design of Separator and Running Pipe in Biomass Pyrolysis Liquefaction Device [J]. Development and Innovation of Mechanical and Electrical Products, 2006,06:41-42.

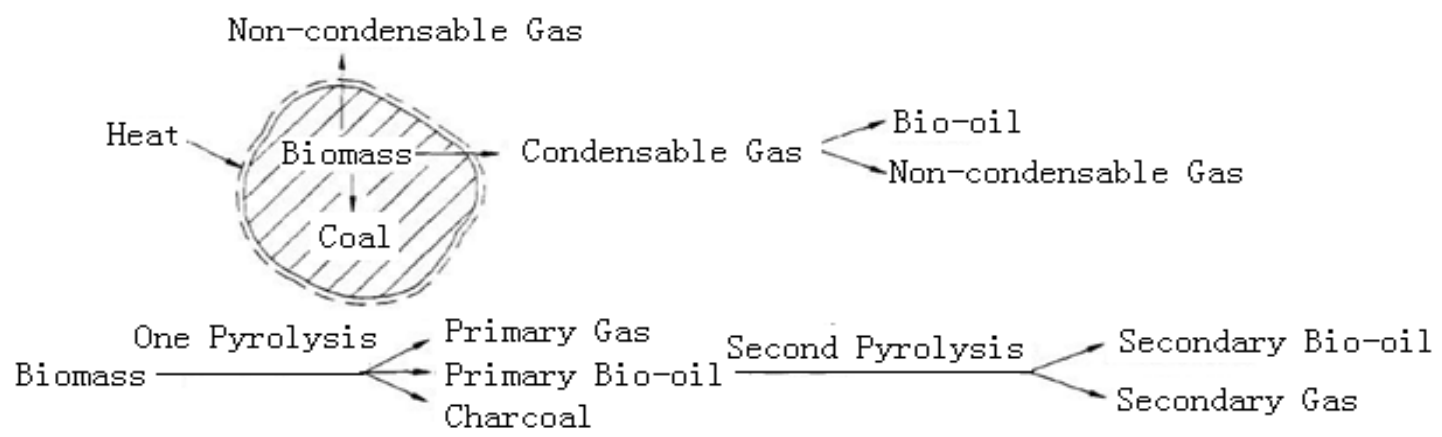

Figure 1 Biomass Pyrolysis Process 